\title{
Pessoa e comunidade: aspectos antropológicos e eclesiológicos nas reflexões pastorais da CNBB
}

\author{
Person and community: \\ anthropological and ecclesiological aspects in the \\ pastoral reflections of the CNBB
}

Leomar Antônio Brustolin

Rafael Martins Fernandes

\section{Resumo}

A atual mudança de época fez com que a Conferência Nacional dos Bispos do Brasil (CNBB) observasse, com renovada atenção, o valor da experiência pessoal de fé no interior da comunidade cristã. No intuito de mostrar o crescente peso que a subjetividade humana assumiu nas reflexões comunitárias do episcopado brasileiro, o presente artigo traça, de modo breve, as principais linhas antropológicas de alguns documentos pastorais publicados pela CNBB desde o período conciliar. A análise antropológica e eclesiológica dos textos permite enxergar, em meio aos diferentes acentos eclesiológicos, uma constante compreensão cristã integral da pessoa. Aqui, a experiência religiosa, na comunidade cristã, é vista sem reducionismos, com atenção especial ao testemunho de vida e à abertura à realidade histórica.

Palavras-chave: Pessoa. Comunidade. Antropologia. Eclesiologia. Igreja.

\section{Abstract}

The current change of age has drawn the CNBB's (National Conference of Brazilian Bishops) renewed attention to the value of a personal faith experience 
within the Christian community. Aiming to demonstrate the considerable weight that human subjectivity has carried in the community reflections of the Brazilian Episcopate, this article briefly outlines the main anthropological lines that have been present in some pastoral documents published by CNBB since the Second Vatican Council period. The anthropological and ecclesiological analysis of the texts will allow us to see, amidst the different ecclesiological accents, the consistent and integral Christian understanding of the person. Here, the religious experience in the Christian community is seen with no reductionism, with special attention to life testimony and openness to the historical reality.

Keywords: Person. Community. Anthropology. Ecclesiology. Church.

\section{Introdução}

Este artigo analisa alguns aspectos do desenvolvimento da compreensão de pessoa nas reflexões sobre a renovação comunitária da CNBB. A particular atenção à pessoa, na comunidade eclesial, terá a vantagem de colocar em evidência a centralidade que o ser humano ocupa na Igreja entendida pelo Episcopado brasileiro.

A relevância dessa temática remete à reflexão sobre a crise de consciência comunitária e o senso de pertença que o individualismo moderno instalou até mesmo entre os agentes da pastoral comunitária. A cultura de privatização e o isolamento determinam o cotidiano de muitas pessoas. Em várias comunidades cristãs, vive-se a fé de forma individualista, atendendo apenas a demandas intimistas. Por outro lado, a crise aponta para a necessidade de redescobrir o valor da relação pessoa-comunidade. Isso implica reconhecer a sede de espiritualidade das pessoas que podem encontrar, na comunidade, um centro mistagógico. A constatação de ambientes descristianizados, no contexto atual, provoca a dimensão missionária. $\mathrm{O}$ vazio e a depressão que ameaçam tantas pessoas poderão ser enfrentados numa comunidade amiga e fraterna, capaz de ser samaritana, acolhendo os caídos pela cultura egoísta e consumista. ${ }^{1}$

A questão antropológica relacionada ao senso eclesial tem sido alvo de crescente interesse de pesquisas realizadas em torno de documentos

\footnotetext{
${ }^{1}$ BRUSTOLIN, L., La conversión pastoral de la parroquia, p. 23.
} 
pastorais do Episcopado brasileiro. ${ }^{2}$ Isso demonstra a difusa percepção da crise de identidade, que afeta o ser humano no atual período de "mudança de época". ${ }^{3}$ De fato, a transformação epocal operada na sociedade globalizada é caracterizada por um exacerbado pluralismo cultural que coloca em xeque as certezas consolidadas há séculos sobre as questões últimas do ser humano.

Perguntas como: "quem é o homem?", ou "de onde ele veio e para onde vai?" são, hoje, naturalmente, relegadas ao âmbito privado. É o indivíduo quem passa a decidir, permanentemente, sobre sua religião, sua sexualidade, seu estilo de vida, seu grupo de pertença e profissão. O desejo de usufruir o tempo presente faz com que questões fundamentais sejam vistas, pelo ser humano globalizado, com certa superficialidade e provisoriedade.

Urge que a Igreja se confronte com essa realidade e faça o discernimento necessário sobre a missão do cristão na contemporaneidade. Este artigo coloca em evidência a convicção da CNBB acerca da necessidade do ser humano de viver numa comunidade de fé, a fim de que ele possa amadurecer de maneira plena e integral. Para realizar tal análise, selecionaram-se quatro momentos históricos dos textos publicados pela CNBB, de modo geral, estreitamente vinculados às Conferências Gerais do Episcopado Latino-Americano. Como se verá, cada momento correspondia a novos desafios, que se identificavam com as Igrejas particulares, o que permite refletir sobre diferentes acentos a respeito da compreensão do ser humano.

\section{A pessoa na renovação comunitária do plano de emergência de 1962}

Os documentos da Conferência do Episcopado brasileiro das décadas de 50 e 60 testemunham o desenvolvimento de nova identidade eclesial no Brasil. O Plano de Emergência, redigido às pressas, antes do Concílio Vaticano II, constituiu a primeira grande expressão dessa nova época. ${ }^{4}$

\footnotetext{
${ }^{2} \mathrm{O}$ recente documento da CNBB Cristãos leigos e leigas na Igreja e na sociedade foi o texto que suscitou estudos mais atentos na disciplina de Antropologia Teológica, ao colocar, no centro de sua atenção, a noção de sujeito para a análise do laicato. (CNBB, Doc. 105). Sobre alguns estudos em torno desse documento: SIGNORELLI, C. F., Leigos e leigas, p. 131-152; AMADO, J. P., Leigos na linha de frente, p. 387-416.

${ }^{3} \mathrm{DAp} 7$.

${ }^{4}$ A CNBB foi fundada em 14 de outubro de 1952, cujo primeiro secretário-geral era o então Mons. Hélder Câmara. Para um estudo mais aprofundado do desenvolvimento eclesiológico das atas, dos estatutos e planos de pastoral do primeiro decênio de existência da CNBB (QUEIROGA, G. F., Conferência Nacional dos Bispos do Brasil).
} 
O Plano de Emergência foi aprovado na $\mathrm{V}$ Assembleia Geral do Episcopado brasileiro em 1962, como resposta aos apelos do Papa João XXIII diante das profundas transformações que ocorriam na América Latina. ${ }^{5}$ De fato, a intensa e desregrada urbanização e os conflitos ideológicos que eclodiram a partir da Revolução Cubana de 1959, exigiam uma rápida resposta evangelizadora das Igrejas particulares no Brasil.

$\mathrm{O}$ avanço das ideias marxistas, no campo e na cidade, demonstrava o descontentamento da imensa população pobre diante das políticas desenvolvimentistas dos governos da década de 50. Para além da ideologia marxista, ganhavam numerosos adeptos, nas fileiras católicas, o naturalismo darwinista, o protestantismo e o espiritismo. Para a Igreja, já não bastavam respostas heroicas dos bispos - normalmente dispersas no vasto território brasileiro; era necessário, sobretudo, somar forças, planejando ações em comum. ${ }^{6}$

A Igreja no Brasil começava a traçar linhas de uma ação realizada em comum pelo conjunto dos seus membros visando a todas as pessoas e seus problemas, no conjunto de áreas e situações que os condicionavam. Isso implicava o levantamento da realidade onde as paróquias se encontravam para um adequado conhecimento dos contextos que influenciavam as circunstâncias da época. Às vésperas do Concílio Vaticano II, a Igreja no Brasil pensava a superação de uma pastoral concentrada na conservação e pretendia uma abertura aos novos desafios que se apresentavam. ${ }^{7}$

O Plano de Emergência apresentou várias ideias renovadoras provenientes dos movimentos: bíblico, litúrgico, teológico e da Ação Católica, as quais, mais tarde, foram ratificadas pelo Concílio Vaticano II. Sob o ponto de vista antropológico, tais movimentos acolhiam, em seu seio, o sujeito moderno com seu olhar mais concreto e histórico sobre a realidade, atento às ciências e inclinado a estabelecer relações mais horizontais com seus semelhantes. ${ }^{8}$ De fato, o plano de 1962 repercutiu essa nova percepção dos sujeitos modernos ao acolher as ideias de recentes estudos bíblicos e ao incentivar o

\footnotetext{
5 Foram dois os pedidos de João XXIII por renovação pastoral ao Episcopado Latino-Americano (JOÃO XXIII, PP., Discurso ao Conselho Episcopal Latino-Americano em sua III Reunião Ordinária de 15 de novembro de 1958, p. 997-1005; JOÃO XXIII, PP., Carta aos Bispos da América Latina, 8 de dezembro de 1961, p. 28-31).

${ }^{6}$ CNBB, Plano de emergência, p. 6-9.

${ }^{7}$ MELO, A. A., A evangelização no Brasil, p. 32-33.

${ }^{8}$ Sobre a presença e a natureza do novo sujeito moderno nos movimentos de renovação teológica do século XX e Vaticano II (LIBANIO, J. B., Concílio Vaticano II).
} 
uso da sociologia religiosa, bem como a valorização do laicato e de algumas experiências comunitárias relevantes desenvolvidas no interior do Brasil.

Apesar de o plano reunir diferentes temáticas, os bispos concentraram a maior parte de sua atenção na renovação das comunidades paroquiais. ${ }^{9} \mathrm{~A}$ ideia central que orienta suas reflexões é a de Igreja como "corpo místico de Cristo", ${ }^{10}$ o que representou para a época um claro resgate dos aspectos mistéricos e comunitários da paróquia. Para levar a cabo a renovação comunitária, o episcopado brasileiro sistematizou a missão da Igreja paroquial a partir da tríplice função de Cristo vivida comunitariamente; ou seja, a paróquia deve ser uma autêntica comunidade de fé (função profética), de culto (função sacerdotal) e de caridade (função real). ${ }^{11}$ A proposta de participação ativa de todos os fiéis, na construção da comunidade, visou à superação da situação de passividade dos fiéis leigos nas liturgias, o seu distanciamento em relação à Sagrada Escritura e o isolamento das comunidades entre si, no apostolado. ${ }^{12}$ Os leigos também foram incentivados a trabalhar na edificação de uma sociedade mais justa e aberta à dimensão transcendente. Aqui, os leigos já não são vistos como "meros executores de ordens, mas companheiros no bom combate". ${ }^{13}$

Outra proposta pastoral que reflete a nova mentalidade comunitária refere-se à multiplicação de pequenas comunidades eclesiais. O Plano de 1962 não apresentava, ainda, a terminologia "Comunidades Eclesiais de Base" (CEBs), mas introduziu a ideia de setorização paroquial para a formação de um amplo e articulado tecido comunitário que já estava presente nesse texto. O Episcopado serviu-se, sobretudo, da experiência pastoral do Movimento de Natal para a elaboração da proposta. ${ }^{14}$ Como procedimento, solicitou-se

\footnotetext{
${ }^{9} \mathrm{O}$ Plano de emergência foi estruturado em três partes: a primeira parte é introdutória, apresentando brevemente a conjuntura eclesial brasileira, bem como algumas linhas de operação da CNBB; a segunda constitui, propriamente, o plano de pastoral; e a terceira, de cunho sociopolítico, contém uma declaração e uma mensagem da CNBB, alertando a população brasileira para os riscos do comunismo e do capitalismo liberal, considerados ateus.

${ }^{10}$ CNBB, Plano de emergência, p. 16.

${ }^{11}$ CNBB, Plano de emergência, p. 17.

${ }^{12}$ CNBB, Plano de emergência, p. 9-10. Contribuem para essa descentralização: o incentivo aos fiéis à leitura da Bíblia; a revitalização da catequese; a promoção do movimento litúrgico, de retiros paroquiais do "Movimento por um Mundo Melhor" (MMM); e a promoção da pastoral de conjunto. ${ }^{13}$ CNBB, Plano de emergência, p. 10.

${ }^{14}$ Ao lado da experiência da Arquidiocese de Natal, o plano cita exemplos de renovação comunitária em paróquias-piloto das dioceses de Ribeirão Preto e de Campinas (CNBB, Plano de emergência, p. 10).
} 
o uso de instrumentos da sociologia para localizar as comunidades naturais existentes na sociedade civil, descobrindo ali lideranças que pudessem formar pequenas comunidades cristãs. ${ }^{15}$

Em termos teológico-pastorais, as propostas do Plano de Emergência deixaram, em segundo plano, uma concepção pastoral corrente na época, de cunho vertical-estático, concentrada na relação presbítero-leigos, visando à salvação individual das almas. ${ }^{16}$ A partir de então, se utilizou uma compreensão mais integral e dinâmica da salvação do ser humano ao se colocar como prioridade a relação calorosa e acolhedora entre todos os fiéis da comunidade. Às vésperas do concílio, a CNBB já antecipava vários traços da renovação comunitária que marcariam as Igrejas particulares no Brasil no período pósconciliar.

Para o estudo do desenvolvimento da compreensão de pessoa na comunidade, colhem-se ao menos duas conclusões desse plano de 1962: a primeira relaciona-se à metodologia pastoral: o fato de os bispos partirem de experiências já realizadas, para indicar rumos na ação pastoral, demonstrou a aplicação de um método indutivo, o que permitiu, na época, uma maior correspondência entre a vida das pessoas e a doutrina, entre os conceitos teológicos e sua aplicação na realidade local. Essa representou uma novidade em relação à teologia neoescolástica reinante até então. A chamada de atenção para a importância da experiência humana na reflexão da fé é uma consequência da chamada "reviravolta antropológica" que estava se impondo na área da Teologia. ${ }^{17}$ A segunda conclusão está em conexão com a primeira e diz respeito ao desenvolvimento de uma noção mais dinâmica de pessoa, dada em perspectiva histórico-comunional. Isto se visibiliza na valorização das características de participação e de justa autonomia dos fiéis leigos na organização das paróquias, bem como na ênfase conferida ao engajamento desses nas realidades terrestres.

\footnotetext{
${ }^{15} \mathrm{O}$ uso da sociologia manifestou-se no pedido de levantamento de dados sobre as realidades social, econômica e religiosa das paróquias e dioceses (CNBB, Plano de emergência, p. 18, 21, 25, 33).

${ }^{16} \mathrm{O}$ Episcopado apresentava um texto muito diferente daquele da Pastoral Coletiva de 1915; um documento emanado das províncias eclesiásticas do Sul e que foi aderido mais tarde por todo o território brasileiro. Tal texto, reeditado em 1950, concentrava sua atenção sobre o pároco, apresentando uma concepção pastoral demasiado jurídica, centralizadora e estática, semelhante a um receituário de normas (BEOZZO, J. O., Igreja no Brasil, p. 466-468).

${ }^{17}$ Sobre o fato da "reviravolta antropológica", ocorrida no campo das ciências modernas, que atingiu os estudos teológicos no decorrer do século XX (BRAMBILLA, F. G., Antropologia Teologica, p. 175-286).
} 


\section{A pessoa na renovação comunitária da primeira etapa de recepção conciliar (1966-1985)}

Os anos que se sucederam ao concílio foram marcados por uma intensa atividade de renovação comunitária no Brasil. Com o apoio da CNBB e do Conselho Episcopal Latino-Americano (CELAM), as dioceses do Brasil promoveram cursos de renovação bíblico-catequética e litúrgica. Conheceu-se uma proliferação de novos ministérios não ordenados e de organismos eclesiais de participação laical. As CEBs ganharam cidadania e se multiplicaram pelo interior do Brasil. No entanto, também é verdade que o clima de euforia veio acompanhado de abusos na reforma litúrgica e da crise do ministério presbiteral, impactando as comunidades católicas.

O "Plano de Pastoral de Conjunto", documento publicado em 1966, pela CNBB, ofereceu grande contribuição aos trabalhos de renovação pastoral das dioceses no primeiro decênio pós-conciliar. $\mathrm{O}$ texto manteve a prioridade expressa no Plano de Emergência pela renovação comunitária, sendo largamente enriquecido pela eclesiologia do Vaticano II. Merece destaque a centralidade do conceito de comunhão nos objetivos do citado plano de 1966, o que reforça a opção do Episcopado brasileiro por uma concepção de ser humano essencialmente relacional-dialogal, noção essa fundamentada a partir da revelação trinitária. ${ }^{18}$

Foi, entretanto, a primeira recepção da Conferência de Puebla (1979) no Brasil que trouxe desdobramentos genuinamente latino-americanos à reflexão sobre a pessoa na comunidade cristã. Nesse período, se evidenciaram os documentos: "Diretrizes Gerais da Ação Pastoral da Igreja do Brasil" (DGAPs), de 1979-1982 e "As Comunidades Eclesiais de Base na Igreja do Brasil”, de 1982. Essas publicações refletem a gradativa tomada de posição no campo sociopolítico por parte da hierarquia da Igreja. De fato, a partir de 1971, os bispos brasileiros alcançaram maior consenso no que diz respeito à necessidade de se manifestar em tom profético a respeito da crise dos direitos humanos, provocada pela Ditadura Militar e ao crescente empobrecimento da população. ${ }^{19} \mathrm{O}$ projeto de "evangelização libertadora" da Conferência de

\footnotetext{
${ }^{18} \mathrm{O}$ objetivo geral da ação da Igreja no Brasil, expresso nesse plano é fundamentalmente comunional: "Levar todos os homens à plena comunhão de vida com o Pai e entre si em Jesus Cristo, no dom do Espírito Santo, pela mediação visível da Igreja" (CNBB, Plano de pastoral de conjunto - 1966-1970, p. 26).

${ }_{19}$ Sobre a mudança de postura do Episcopado brasileiro em face da Ditadura Militar (GODOY, M. J., CNBB, p. 132-139).
} 
Puebla foi, então, amplamente assumido nesses documentos e expressou uma imagem de Igreja prevalentemente ad extra, comprometida com as aspirações das camadas sociais mais pobres. ${ }^{20}$

Os novos desdobramentos na concepção de pessoa são percebidos no objetivo geral das DGAPs, 1979-1982, sobretudo pela introdução das expressões "libertação integral do homem" e "opção pelos pobres". Tais noções não estão em desacordo com a compreensão subjacente de pessoa como ser de comunhão, presente no plano anterior, ou seja, de 1966. Afinal, a meta da "libertação de todos os homens e do homem todo" 21 vinha a ser a aplicação criativa da categoria comunhão no contexto latino-americano de repressão militar e de dependência econômica.

Aqui, a liberdade é vista como o dom por excelência concedido pelo Deus de Jesus Cristo ao ser humano e é a condição de possibilidade para a realização autêntica da comunhão entre as pessoas..$^{22} \mathrm{O}$ conteúdo da libertação está fundamentado na pessoa de Jesus Cristo a partir do texto programático de Lc 4,18: “O Espírito do Senhor está sobre mim porque ele me ungiu para evangelizar os pobres". ${ }^{23}$ É a partir da pessoa de Jesus que se desenvolve o acento social, comunitário e participativo da libertação integral do ser humano.

O documento sobre as CEBs, de 1982, se inseriu nas reflexões das DGAPs - 1979-1982 explicitando a opção do Episcopado do Brasil por uma estrutura comunitária alternativa que estivesse, fundamentalmente, a serviço do projeto de evangelização libertadora. Nesse contexto, a estrutura paroquialtradicional foi vista como insuficiente para a realização do ideal de libertação: a paróquia foi apresentada como centralizadora e distante dos pobres. ${ }^{24} \mathrm{~A}$ solução passou a ser vista a partir do modelo comunitário, experimentado nas CEBs, caracterizado pela descentralização das estruturas eclesiais, pelo protagonismo dos leigos na animação das comunidades, pela fraternidade, pela entreajuda e pelo empenho pela justiça.

${ }^{20}$ Para uma melhor compreensão e aprofundamento da recepção da Conferência de Puebla nos documentos da CNBB do período (FREITAS, M. C., Uma opção renovadora, p. 204-207).

${ }^{21}$ CNBB, Doc. 15, 29.

${ }^{22} \mathrm{O}$ enlace entre comunhão e libertação é expresso no objetivo geral do Doc. 15: "Evangelizar a sociedade brasileira em transformação, a partir da opção pelos pobres, pela libertação integral do homem numa crescente participação e comunhão, visando à construção de uma sociedade fraterna, anunciando, assim, o Reino definitivo".

${ }^{23}$ CNBB, Doc. 15,8 .

${ }^{24}$ CNBB, Doc. $25,43,46$. 
No centro das atenções, está a salvação integral do ser humano: pobre, massificado e fragilizado pela política de Segurança Nacional, que deve ser resgatado em sua dignidade pela comunidade cristã, tornando-se sujeito de transformação da sociedade..$^{25}$

Do ponto de vista antropológico, as reflexões da CNBB, no período pós-Puebla, estão em plena continuidade com o Plano de 1966, que apresentou uma noção dinâmica e comunional de pessoa. A novidade está na ênfase concedida ao aspecto social da salvação cristã - uma redescoberta das Conferências de Medellín e de Puebla -, ressaltando a intrínseca unidade entre o social e o individual, entre a salvação do corpo e da alma, entre fé e vida.

A acentuação do aspecto social da salvação propiciou, então, um olhar mais atento aos brasileiros, na sua grande maioria, social e economicamente pobres. Na fundamentação antropológica subjacente aos documentos de 1979 e 1982, o acento principal recai, dessa vez, sobre a encarnação do Verbo de Deus: é Cristo que mostra a verdadeira dignidade do ser humano, especialmente dos pobres deste mundo. Não foi suficientemente trabalhada pela reflexão comunitária da CNBB, nesse período, a diversidade de rostos dos pobres, como o rosto do índio e do negro, historicamente escravizados. ${ }^{26}$ A experiência pessoal religiosa, bem como a diversidade de religiosidade popular do catolicismo brasileiro também parecem pouco presentes, o que se justificaria pelo grande peso que a reflexão de cunho social assumiu naquela época. ${ }^{27}$

\section{Redescoberta da dimensão subjetiva da fé no final dos anos 80}

Na segunda metade da década de 80 , já se fazia sentir, nos meios eclesiais, a presença de novo paradigma. ${ }^{28}$ Ao lado dos problemas sociopolíticos que

\footnotetext{
${ }^{25} \mathrm{O}$ grande destaque que o documento de 1982 oferece à dimensão sociotransformadora das CEBs comprova essa perspectiva social da libertação cristã. Todo o documento é perpassado pelo aspecto sociotransformador (CNBB, Doc. 25, 43-88.)

${ }^{26}$ No Doc. 15, o pobre é basicamente o ser humano excluído das benesses econômicas. Contudo, existe nesse texto uma citação dos migrantes (n. 99) e outra para o trabalho da pastoral "afro -brasileira" (n. 93).

${ }^{27}$ Os ns. 89 e 90 do Doc. 15 tratam da piedade popular. No final da década de 90, Alberto Antoniazzi apontava ao esquecimento do aspecto subjetivo da experiência religiosa nas reflexões do Episcopado brasileiro desse período, atribuindo o fato ao forte peso institucional dessa Conferência de Bispos (ANTONIAZZI, A., Planejamento pastoral, p. 110).

${ }^{28}$ Para uma análise da passagem de um paradigma social de compreensão da realidade para outro de cunho cultural (TOURAINE, A., Un nouveau paradigme).
} 
dominavam a agenda dos países latino-americanos, emergiram questões culturais que tornaram mais complexa a vida em sociedade. É a época da lenta reabertura democrática no Brasil, que fazia a sociedade respirar ares de maior liberdade, podendo organizar-se política e ideologicamente de modo mais plural. De outra parte, o acentuado crescimento das cidades contribuía para o advento da globalização, propiciando a opção por novos valores e uma consequente leitura mais diversificada da realidade. Isso se verificou no campo religioso com o fenômeno da multiplicação de movimentos e de seitas religiosas autônomas.

A publicação, em 1988, do documento "Igreja: comunhão e missão na evangelização dos povos, no mundo do trabalho, da política e da cultura", ${ }^{29}$ manifestou um esforço de adequação do Episcopado para o novo período, e, igualmente, a formação de nova síntese eclesiológico-pastoral em suas reflexões. ${ }^{30}$ As ideias de comunhão e de missão do referido documento reforçaram a imagem comunional de ser humano em uma perspectiva aberta e dialogal, fundamentada na teologia trinitária e no movimento de encarnação do Filho de Deus.

Nesse período, evidencia-se o aparecimento de algumas intuições dos bispos no que diz respeito à valorização da dimensão subjetiva da fé. Em primeiro lugar, surge, de modo discreto, o papel da subjetividade feminina na comunidade cristã. Ao lado da referência antropológica fundamental de Jesus Cristo, aparece a figura materna de Maria. Esta afirmação, mesmo sendo bastante óbvia, é importante por fazer notar a polaridade antropológica masculino-feminino, demonstrando uma maior sensibilidade do Episcopado diante do modo feminino de vivenciar a fé. ${ }^{31}$

Outra intuição presente no documento: "Igreja: comunhão e missão", diz respeito à introdução de um quadro esquemático contendo os três níveis de experiência humano-religiosa e essenciais a uma compreensão mais ampla da vida comunitária: "O nível da pessoa. [...] O nível do grupo ou da pequena comunidade. [...] O nível de articulação mais ampla". ${ }^{32}$ A referida distinção

\footnotetext{
${ }^{29}$ CNBB, Doc. 40.

${ }^{30}$ Esse documento fundamenta toda a ação eclesial na comunhão trinitária e no movimento missionário de encarnação do Filho de Deus entre os homens. Dessa fundamentação, emerge, com força, o papel da comunidade cristã para não se fechar em pequenos grupos, mas se inserir na história, especialmente no mundo dos pobres (CNBB, Doc. 40).

${ }^{31}$ CNBB, Doc. 40, 53-55.

${ }^{32}$ CNBB, Doc. 40, 93-95.
} 
também é nova, o que sinalizou, de alguma forma, o abandono de um estilo de reflexão comunitarista presente na década de 70 e no início dos anos 80 , no qual as diferentes experiências de fé, vivenciadas por pessoas e grupos, eram pouco notadas e valorizadas. ${ }^{33}$

Endossa essa perspectiva plural de análise da vida comunitária um breve aceno do documento sobre o papel positivo da paróquia como espaço de comunhão entre grupos, comunidades e movimentos. ${ }^{34}$ Até mesmo a opção preferencial pelos pobres foi concebida nessa perspectiva plural, de tal forma que se mencionam, agora, os povos indígenas, os ciganos, a população negra e os migrantes. ${ }^{35}$

A valorização das diversas subjetividades, no interior da comunidade de fé, é um dado que mostra a capacidade da CNBB de dar acolhimento e de se adequar aos novos sinais dos tempos. Tal perspectiva já antecipava, de algum modo, o projeto de "evangelização inculturada" que foi proposto pela Conferência Episcopal Latino-Americana, em Santo Domingo, 1992.

\section{A pessoa como sujeito nas reflexões da CNBB pós-Aparecida}

A virada do novo milênio foi marcada por avanços científicos e tecnológicos que impactaram, de maneira gigantesca, as culturas humanas. Foi nesse período que se começou a falar em "mudança de época", ${ }^{36}$ como também foi ali que ganharam espaço, nos meios acadêmicos, conceitos como: pós-humano e pós-cristianismo. Verificou-se um distanciamento e uma hostilidade crescentes na sociedade globalizada, ante a tradição cristã, além de uma notável fragmentação do cenário religioso latinoamericano. A Conferência de Aparecida, em 2007, buscou responder a esses desafios, propondo uma configuração eclesial mais adaptada ao sujeito globalizado. ${ }^{37}$

\footnotetext{
${ }^{33} \mathrm{O}$ comunitarismo, isto é, a forte acentuação da pequena comunidade ou das CEBs nos escritos eclesiológicos brasileiros das décadas de 70 e 80 , em detrimento de outras dimensões, pode ser observado na CNBB através das Diretrizes Gerais da Ação Pastoral, dos Planos bienais de 1974 e 1984 e na publicação de documento sobre as CEBs de 1982. As DGAPs - 1987-1990, por sua vez, revelam uma mudança ao suplantar a prioridade das CEBs pela evangelização nos meios de comunicação social (CNBB, Doc. 38, 147-242).

${ }^{34} \mathrm{CNBB}$, Doc. 40, 94.

${ }^{35}$ CNBB, Doc. 40, 235, 236, 255, 259, 260.

${ }^{36}$ DAp 44.

${ }^{37}$ Miranda, em seu comentário sobre a Conferência de Aparecida, chama a atenção para essa
} 
Vale dizer que, sob o ponto de vista antropológico-pastoral, Aparecida aprofundou algumas intuições já presentes no final dos anos 80 , apresentando uma configuração eclesial que oferecesse destaque à experiência pessoal de fé. O elevado número de usos de categorias com conotação mais experiencial, como "encontro pessoal com Jesus Cristo" e "discípulos missionários", revela esse voltar-se da instituição eclesial para a dimensão pessoal da fé.

É importante reconhecer o esforço da CNBB em aplicar as orientações da Conferência de Aparecida nas Igrejas particulares no Brasil. Para este estudo sobre a pessoa na comunidade, vale a pena destacar os seguintes documentos do período: "Comunidade de comunidades: uma nova paróquia" (2014) e "Cristãos leigos e leigas na Igreja e na sociedade" (2016).

No documento "Comunidade de comunidades", a noção de sujeito eclesial apareceu no Capítulo 3 denominado "sujeitos e tarefas da conversão paroquial". ${ }^{38} \mathrm{O}$ uso de tal noção, no documento, se justifica a partir da convicção de que a renovação da comunidade paroquial não pode acontecer separada da conversão pessoal. Aqui, o sujeito da "nova paróquia" é, necessariamente, o discípulo missionário, ou seja, aquele que fez um encontro pessoal com Jesus Cristo, o "Bom Pastor". As características proximidade e cuidado para com todos, especialmente com os pobres, são marcas de Jesus, o Bom Pastor e orientam o processo de conversão dos discípulos no seio da comunidade cristã.

O Documento 100 também destaca a urgência de uma acolhida personalizada na comunidade. Numa sociedade que, facilmente, tende à despersonalização, as famílias começam a ter dificuldades de manter/formar vínculos afetivos. Muitos idosos e doentes sentem-se um peso até mesmo em sua casa. A comunidade cristã há de promover o humanismo integral e solidário, ${ }^{39}$ capaz de colocar a pessoa no centro de suas ações, sendo capaz de devolver a dignidade que outras instâncias tolheram. A personalização da pastoral será um dos exercícios mais pesados delegado à comunidade, pois seus membros devem ser preparados para uma alteridade outra que a sociedade atual nem sempre compreende. ${ }^{40}$

reconfiguração eclesial das Igrejas Latino-Americanas (MIRANDA, M. F., A eclesiologia do Documento de Aparecida, p. 843-864).

${ }^{38}$ CNBB, Doc. 100, 192-241.

${ }^{39}$ PONTIFÍCIO CONSELHO JUSTIÇA E PAZ, Compêndio de Doutrina Social da Igreja, 5.

${ }^{40}$ BRUSTOLIN, L. A., La conversión pastoral de la parroquia, p. 24. 
Isso implicará uma conversão pastoral-pessoal, segundo o Documento 100. A conversão do indivíduo em sujeito eclesial acontece com a ajuda indispensável de uma comunidade mistagógica que priorize o itinerário de fé da pessoa. Isso se desdobra nos seguintes passos: a acolhida calorosa para todos que tiverem contato com a comunidade paroquial ${ }^{41} \mathrm{o}$ acompanhamento catequético gradual e personalizado que envolva toda a comunidade $;{ }^{42}$ a introdução do indivíduo na vida e na missão da pequena comunidade em comunhão com a comunidade paroquial $;{ }^{43}$ oferecimento de instrumentos, como a formação permanente, para que a pessoa se torne sujeito da missão. ${ }^{44}$

Sob essa perspectiva comunional, aparecem diferentes sujeitos na composição da vida comunitária. Os presbíteros são concebidos, principalmente, como discípulos apaixonados de Cristo-Pastor. São suas experiências com o Cristo vivo que os movem a uma vivência mais comunitária do seu ministério ordenado, distribuindo funções, indo ao encontro das pessoas afastadas da comunidade. ${ }^{45}$ Por sua vez, os religiosos são chamados a desenvolver seus carismas específicos nas comunidades e famílias onde a vida se encontra mais ameaçada. ${ }^{46}$ Os leigos também são inseridos em um contexto profundamente comunitário e missionário, com preocupação especial sobre as famílias, as mulheres, os jovens e os idosos. ${ }^{47}$

$\mathrm{O}$ aspecto missionário evita uma visão de leigos fechados dentro das comunidades, com receio de assumirem o que é do mundo. Eles são chamados a viver o discipulado missionário de Cristo na Igreja e no mundo, nas mais variadas situações onde exercem suas atividades.

O documento sobre cristãos leigos e leigas merece particular atenção por sistematizar alguns princípios antropológicos sempre defendidos pela Conferência Episcopal brasileira e que fundamentam a missão dos fiéis leigos. Na subseção dedicada à antropologia cristã, ${ }^{48}$ os bispos explicitaram

${ }^{41}$ CNBB, Doc. 100, 257-267.

${ }^{42}$ CNBB, Doc. 100, 268-270.

${ }^{43}$ CNBB, Doc. 100, 244-256.

${ }^{44}$ CNBB, Doc. 100, 281-308.

${ }^{45}$ CNBB, Doc. 100, 199-205.

${ }^{46}$ CNBB, Doc. 100, 207-209.

${ }^{47}$ CNBB, Doc. 100, 210-227.

${ }^{48} \mathrm{O}$ fato de existir uma subseção dedicada especificamente à antropologia cristã - algo não usual nas reflexões da CNBB - reflete um crescente interesse dela em aprofundar a identidade do ser humano à luz da fé. Sobre essa subseção (CNBB, Doc. 105, 119-135). 
a noção de "sujeito eclesial". De raiz judaico-cristã, a palavra sujeito ganha pleno significado na fé em Jesus Cristo. É a partir d'Ele que se entende, com toda profundidade, o significado das características humanas de liberdade, autonomia e relação. Pela oferta que Cristo faz de sua própria vida na cruz e por sua ressurreição, o ser humano torna-se verdadeiramente liberto, sujeito de novas relações fraternas. ${ }^{49}$

Como consequência, a comunidade cristã é vista como o lugar que educa e que testemunha uma convivência renovada:

A Igreja é a comunhão de libertos para uma vida nova, para o serviço, em harmonia e respeito. Ela é chamada a testemunhar uma convivência humana renovada, em relações fraternas, em comunhão libertadora. A verdadeira comunhão cristã gera autonomia, liberdade e corresponsabilidade; por sua vez, estas são necessárias para a autêntica comunhão (Gl 2,1-2.9.11). ${ }^{50}$

É válido assinalar, ainda, no que diz respeito à valorização das diferentes subjetividades no interno das comunidades, a afirmação do Episcopado brasileiro sobre os perfis mariano, apostólico e petrino da Igreja. Na Igreja, entendida como comunhão de pessoas, a valorização de tais perfis faz notar, no interior da própria communio sanctorum, a existência de diversidade e complementaridade de carismas, sem anulação de opostos ${ }^{51}$ Essa compreensão permite entender a necessidade de convivência e de unidade na missão de grupos e de movimentos com espiritualidades diferentes, que participam da mesma comunidade paroquial ou diocese. Não há pessoas ou grupos eclesiais superiores aos outros. A única pessoa que possui precedência em Cristo é Maria, a toda santa e rainha dos apóstolos. Ela indica para o ser humano que o maior objetivo a ser alcançado é a santidade. Em Jesus Cristo, ela é modelo às nossas comunidades eclesiais.

Como exemplo de aplicação dos princípios antropológicos acima expressos, os bispos citam a promoção do "Conselho de Leigos" nas comunidades eclesiais. Tais organismos favorecem a geração de processos participativos, educando fiéis presbíteros, religiosos e leigos para uma

\footnotetext{
${ }^{49}$ CNBB, Doc. 105, 123-127.

${ }^{50}$ CNBB, Doc. 105, 126.

${ }^{51}$ CNBB. Doc. 105, 113-115. Para uma análise mais aprofundada dos perfis ou dos princípios existentes na Igreja (BALTHASAR, H. U. Von., Le complexe antiromain, p. 162-172).
} 
adequada autonomia, fortalecendo o sentido de unidade e de abertura ao diálogo. ${ }^{52}$

\section{Conclusão}

Nesta análise de alguns documentos da CNBB sobre a relação pessoacomunidade, verificou-se que não houve uma preocupação do Episcopado brasileiro em sistematizar os conteúdos de uma antropologia teológica. Contudo, se apreende do pensamento antropológico contido nos textos da CNBB, uma imagem bem clara de ser humano. É a imagem do ser humano iluminada pelo mistério de Deus Trindade e pela encarnação de seu Filho. $\mathrm{Na}$ essência da criatura humana, está, então, o chamado à comunhão e à liberdade divinas. Tal concepção cristã e integral de ser humano fundou uma proposta às Igrejas particulares no Brasil de promoção de comunidades pequenas, com o resgate das pessoas fragilizadas, pobres e excluídas, bem como concedeu atenção à diversidade de raças e culturas, que compõem o povo brasileiro.

A estipulação, nesta pesquisa, de diferentes etapas dos documentos da CNBB mostrou a capacidade dos bispos de se adaptarem a diferentes contextos, respondendo às várias visões/conceitos de ser humano. Assim, houve desdobramentos novos nas reflexões do Episcopado sobre a pessoa na comunidade. $\mathrm{Na}$ década de 60 , intensificaram-se os traços essencialmente comunitários e participativos, e, nas décadas de 70 e 80, houve a descoberta da dimensão social da salvação cristã, explicitada pela noção de "libertação integral do homem". No período atual - de mudança de época - verifica-se a valorização da dimensão pessoal da fé, ressaltando a pessoa como um sujeito capaz de fazer uma experiência de fé consciente e livre, respaldada pela comunidade mistagógica, bem como a constatação do respeito aos diferentes modos de expressar a fé.

Como foi demonstrado, este crescente peso que a reflexão sobre a subjetividade humana assumiu nos documentos da CNBB, não reflete uma compreensão desequilibrada de pessoa, nem quer ser uma fuga do Episcopado perante as realidades terrestres. Pelo contrário, demonstra uma sensibilidade destes bispos para o diálogo com a sociedade globalizada.

$\overline{{ }^{52} \text { CNBB, Doc. } 105,127 .}$ 
Aliás, para esta sociedade, que tende a pensar o ser humano de modo fragmentado, tantas vezes reduzindo-o aos aspectos subjetivos, a CNBB oferece como alternativa um entendimento de experiência religiosa que se alcança na totalidade da pessoa. A ênfase do Episcopado no fato da encarnação do Verbo de Deus aponta para uma experiência de fé que não só abarque os sentimentos, mas que priorize o testemunho de vida e a abertura à realidade histórica.

\section{Referências bibliográficas}

AMADO, J. P. Leigos na linha de frente? Uma reflexão a respeito do laicato no atual momento evangelizador. Atualidade Teológica, v.20, n.53, p. 387-416, mai./ago. 2016. Disponível em: <https://www.maxwell. vrac.puc-rio.br/27085/27085.PDFXXvmi=>. Acesso em: 03 ago. 2018.

ANTONIAZZI, A. Planejamento pastoral: reflexões críticas. Perspectiva Teológica, v.21, n.53, p. 101-112, mai./ago. 1989. Disponível em: $<$ http:// faje.edu.br/periodicos/index.php/perspectiva/article/view/1786/2105>. Acesso em: 05 set. 2018.

BALTHASAR, H. U. Von. Le complexe antiromain. Trad. de Willibrorda. Paris: Mediaspaul, 1998.

BEOZZO, J. O. Igreja no Brasil: o planejamento pastoral em questão. REB, v.42, n.167, p. 465-505, set. 1982.

BRAMBILlA, F. G. Antropologia Teologica. In: CANOBBIO, G.; CODA, P. (Org.). La Teologia del XX secolo: un bilancio. Roma: Città Nuova, 2003. p. $175-286$. v. 2.

BRUSTOLIN, L. A. La conversión pastoral de la parroquia: la renovación parroquial en América Latina. Rivista Lateranum, v.80, n.1, p. 9-26, jan. 2014.

CELAM. V Conferência Geral do Episcopado Latino-Americano e do Caribe. Documento conclusivo. Aparecida, 13 a 31de maio de 2007. São Paulo: Paulinas, 2007.

CNBB. As Comunidades Eclesiais de Base na Igreja do Brasil. São Paulo: Paulinas, 1982. (Doc. 25). 
CNBB. Comunidade de comunidades: uma nova paróquia: a conversão pastoral da paróquia. São Paulo: Paulinas, 2014. (Doc. 100).

CNBB. Cristãos leigos e leigas na Igreja e na sociedade: sal da terra e luz do mundo (Mt 5,13-14). São Paulo: Paulinas, 2016. (Doc. 105).

CNBB. Diretrizes gerais da ação pastoral da Igreja no Brasil - 1979-1982. São Paulo: Paulinas, 1979. (Doc. 15).

CNBB. Diretrizes gerais da ação pastoral na Igreja do Brasil - 1987-1990. São Paulo: Paulinas, 1987. (Doc. 38).

CNBB. Igreja: comunhão e missão na evangelização dos povos, no mundo do trabalho, da política e da cultura. São Paulo: Paulinas, 1988. (Doc. 40).

CNBB. Plano de emergência. Rio de Janeiro: Dom Bosco, 1962.

CNBB. Plano de pastoral de conjunto - 1966-1970. Rio de Janeiro: Dom Bosco, 1966.

FREITAS, M. C. Uma opção renovadora: a Igreja no Brasil e o planejamento pastoral: estudo genético-interpretativo. São Paulo: Loyola, 1997.

GODOY, M. J. CNBB: Conferência Nacional dos Bispos do Brasil. In: PASSOS, J. D.; SANCHEZ, W. L. (Ed.). Dicionário do Concílio Vaticano II. São Paulo: Paulinas, 2015. p. 132-139.

JOÃO XXIII, PP. Carta aos Bispos da América Latina, 8 de dezembro de 1961. AAS 54, p. 28-31, 1962.

JOÃO XXIII, PP. Discurso ao Conselho Episcopal Latino-Americano em sua III Reunião Ordinária de 15 de novembro de 1958. AAS 50, p. 997-1.005, 1958.

LIBANIO, J. B. Concílio Vaticano II: em busca de uma primeira compreensão. São Paulo: Loyola, 2005.

MELO, A. A. A evangelização no Brasil: dimensões teológicas e desafios pastorais. Roma: Editrice Pontificia Università Gregoriana, 1996.

MIRANDA, M. F. A eclesiologia do Documento de Aparecida. REB, v.67, n.268, p. 843-864, out./dez. 2007.

PONTIFÍCIO CONSELHO JUSTIÇA E PAZ. Compêndio de Doutrina Social da Igreja. São Paulo: Paulinas, 2005.

QUEIROGA, G. F. Conferência Nacional dos Bispos do Brasil: comunhão e corresponsabilidade. São Paulo: Paulinas, 1977. 
SIGNORELLI, C. F. Leigos e leigas: sujeitos eclesiais? Reflexões sobre o Caderno 107. REB, v.75, n.297, p. 131-152, jan./mar. 2015.

TOURAINE, A. Un nouveau paradigme: pour comprendre le monde d'aujourd'hui. Paris: Fayard, 2005.

\section{Leomar Antônio Brustolin}

Doutor em Teologia pela Universidade São Tomás de Aquino (Roma) Docente de Teologia na Pontifícia Universidade Católica do Rio Grande do Sul Porto Alegre / RS - Brasil E-mail: leomar.brustolin@pucrs.br

Rafael Martins Fernandes

Doutor em Teologia pela Universidade Lateranense (Roma) PNPD - Capes pelo PPG em Teologia da Pontifícia Universidade Católica do Rio Grande do Sul Porto Alegre / RS - Brasil E-mail: rafaelmartinsfernandes@yahoo.com.br

Recebido em: 01/10/18

Aprovado em: 25/01/19 